\title{
O HOMEM E OS INSETOS, PASSADO, PRESENTE, FUTURO*
}

É altamente gratificante voltar a esta Escola de Saúde Pública, a que tanto devo: lições, exemplos, colaboração esclarecida e responsável, e amabilidades como a que é consubstanciada pelo convite que ora atendo.

Comemoramos o cinqüentenário de um laboratório que se transformou num grande Departamento com notável acervo de serviços prestados à ciência e à Saúde Pública.

Outros, mais qualificados, melhor poderiam comentar os trabalhos e realizaçōes do Laboratório de Entomologia da Faculdade de Saúde Pública. Certo de que todos os preesntes os conhecem melhor do que eu, e consciente de minhas limitações, restringir-me-ei a propor- lhes uma reflexão sobre a evolução das interações Homem-Inseto, com vistas a uma indagação prospectiva.

Antes, porém, permitam-me reverenciar a memória de um dos notáveis iniciadores do Laboratório cujo cinqüentenário comemoramos. Refiro-me a Nelson Cerqueira, com quem tive o privilégio de privar no Instituto Nacional de Pesquisa da Amazônia, na década de 60. Operoso e capaz, Cerqueira foi um infatigável pesquisador no campo, um Mestre generoso compartilhando seu saber com os jovens que lhe foram confiados. Deixou discípulos que mereceram expressivos elogios de especialistas estrangeiros que se valeram de sua colaboração. Já com grave insuficiência cardíaca, recusava a merecida e indicada licença, trabalhando heroicamente até a última hora. Não teve tempo para amealhar bens materiais e foi sepultado em Manaus, em jazigo perpétuo conseguido pelo IMPA a despeito de obstinadas e desumanas resistências burocráticas.

Por coincidência, quando se fundava o Laboratório que homenageamos, também eu iniciava a minha longa jornada pelos caminhos ásperos da Saúde Pública.

Terminava o meu curso médico na velha Faculdade da Praia Vermelha, hoje demolida pela picareta e pelas reformas de caráter involutivo.

Na Baixada Fluminense os únicos esquadrões da morte eram formados por anofelinos, aplicados transmissores da malária. No hospital, afirmava-se com absoluta convicção: malária não ataca os postes da Light, mas cada doente proveniente da baixada é suspeito de malária até prova em contrário.

Assim, terminei o meu curso médico em contato quotidiano com o binômio anofelino-malária, uma interação Homem-Inseto de todos conhecida.

O laboratório clínico entrava em uma fase de ouro com as recentes conquistas da bioquími$\mathrm{ca}$, da enzimologia, da imunologia, da hematologia, da endocrinologia. Eletrocardiógrafos e eletroencefalógrafos começavam a ser introduzidos no Brasil. Surgiam as sulfas. Equipamentos sofisticados começavam a ser utilizados e vivia-se uma ânsia de modernização.

Porém, mesmo os mais jovens, mau grado o inevitável fascínio de um caso de hipocalcemia, de hiperkalihemia ou de anemia aplástica, mesmo os mais incontidos caçadores de raridades clínicas, todos reconheciam como prioritárias as prosáicas febres que matavam na baixada fluminense. Forçoso era reconhecer que, para a Saúde Pública, a velha malária era mais importante do que um adenoma das ilhotas de Langerhans, uma permanência do buraco de Botal ou uma tireoidite linfomatosa de Hashimoto. O que não impedia que jovens como eu, mesmo naquela época, despreparados para adicionar algo de válido a discussão de temas já estudados em profundidade, se encantassem com a publicação de um caso de patologia rara.

Passou-se meio século.

A recuperação da saúde individual, armada de espetaculares recursos tecnológicos, dispendiosa e portanto altamente rentável, substituiu, nas políticas de saúde a preocupação com a preservação da saúde, atividade requerendo muita célula cinzenta, muito trabalho, sem oferecer benefícios aos mercadores de equipamentos, medicamentos e serviços.

A malária praticamente desapareceu nas regiões menos subdesenvolvidas, tornou-se doença exótica atacando populações desconhecidas

\footnotetext{
Palestra proferida em 19 de agosto de 1987, pelo Prof. Dr. Paulo de Almeida Machado, a convite da Congregação da Faculdade de Saúde Pública, como parte das comemorações do "Cinquientenário do Laboratório de Entomologia".
} 
vivendo em locais distantes e ignorados. $\vec{E}$ como se fosse endemia grassando em outro planeta. Como outras moléstias infecciosas e parasitárias, e mesmo a glamorosa AIDS, interessa sobretudo a alguns bancos de sangue por trazerem uma grande ameaça: poder comprometer o êxito de um procedimento cirúrgico de alta tecnologia. Minorar o sofrimento, prevenir doenças, passaram a um segundo plano, quando se tornou possível decidir sobre a duração da vida e até conseguir prolongá-la com certo êxito para uma minoria privilegiada.

Nesta conjuntura de poder e sucesso, aqui nos encontramos para comemorar o cinquientenário de um centro de entomologia médica.

Pouco sabemos do passado longínquo da espécie humana, embora muito já tenha sido descoberto graças a pertinácia dos paleo-antropólogos, associada a capacidade do raciocínio lógico.

Para todas as espécies, a sobrevivência dependeu antes de tudo de um relacionamento razoável com a Natureza. Os primitivos prosímios, e seus sucessores, não seriam exceção. A numerosa população de insetos certamente não escapou à observação e curiosidade daqueles seres primitivos, durante 3 a 6 milhões de anos.

O Plesiadapis, talvez o mais antigo fóssil de prosímio, era um insectívoro.

Quem não observou um macaco procurando atenta e aplicadamente os insetos passeando entre os pêlos de outro? $\vec{E}$ sem dúvida um espetáculo curioso. Para temperamentos sensíveis, uma enternecedora manifestação de solidariedade ou mesmo de afeto. Um cientista menos romântico, interpretaria a cena comovedora como uma simples procura de alimento. Afinal, insetos são proteína animal, necessária à dieta dos macacos que levam aos dentes cada um dos bichinhos que encontram entre os pêlos do "amigo".

Não seria fantasioso imaginar que nossos honoráveis antepassados, menos remotos, fossem eles do gênero Ramapithecus ou do gênero Australopithecus, também explorassem a pelagem de seus amigos a procura de alimento. Durante milhões de anos, insetos foram fonte de proteína animal utilizada pelos primatas. Ainda em nossos dais, insetos são considerados saborosas iguarias por diversos povos. Podem-se encontrar "lagartas grelhadas" no cardápio de um restaurante na África Equatorial; na América Latina, mesmo em núcleos urbanizados comem-se insetos; as populações primi- tivas da Amazônia regalam-se com larvas de coleópteros vivendo na madeira em decomposição; no Chapadão dos Pareci, os índios comem "tucuras", enormes gafanhotos com belas asas coloridas e que artisticamente espetados num espinho de siriva são cuidadosamente moqueados, ganhando o aspecto de camarões; em todo o Brasil, enquanto existiam bastante formigueiros, um prato de fritada de içás era iguaria nada desprezível.

Parece indiscutível que a interação Homem-Inseto iniciou-se com a predação pelo Homem. O Homem via no inseto um alimento.

Há pelo menos 4.000 anos, foi iniciado um novo tipo de interação: a exploração de produtos elaborados pelos insetos. O Homem passou a se interessar pelo inseto como um produtor de riqueza. Dois mil anos antes de Cristo foram talhados os relevos do templo de Neuserre, no Egito, contendo referências à seda e ao mel que já eram considerados produtos nobres.

Aliás, ainda o são até hoje, apesar das fibras sintéticas e do melado de cana rotulado impunemente como "puro mel".

São citadas referências a insetos, seda ou mel que constariam de antigos textos chineses, hindus, árabes e hebreus.

Mas já os egípcios começaram a se preocupar com insetos também como seres incômodos.

Num papiro de 1.500 a.C., encontram-se fórmulas para repelir ou matar vespas, pulgas e piolhos. Teve início um terceiro tipo de interação, a tentativa de controle das populações de insetos.

Dois séculos antes de Cristo, iniciava-se, com Aristóteles, a quarta fase. Aqueles seres bizarros, de vida breve, origem desconhecida, que não tinham sangue e sofriam tão dramáticas metamorfoses, poderiam fornecer também informações sobre a própria vida. $O$ inseto não é mais um mero alimento, não é apenas um produtor de mel e seda, não é apenas um ser incômodo que cumpre repelir ou exterminar. $O$ inseto passa a ser objeto de pesquisa científica e filosófica.

Aristóteles foi o primeiro a se ocupar de insetos, como naturalista e com espírito científico. Seus tratados "As partes dos animais" e "A geração de animais", são os primeiros textos sistematizados de biologia. Devem-se também a Aristóteles estudos pioneiros sobre a anatomia e até as primeiras referências a his- 
tologia além de notáveis tentativas de classificação de animais, utilizando critérios científicos e por vezes contraditando Platão ao rejeitar critérios dicotomizantes. O reconhecimento do sexo dos animais, a refutação da panspermia, os estudos sobre a reprodução de insetos, caracterizam Aristóteles como o primeiro biólogo, um naturalista de assombrosa fecundidade.

Em Roma, por volta do ano 60 da era cristã, Plínio, o Velho, retomava o estudo da Natureza, com notável saber, mas sem contribuiçōes originais de maior vulto.

Seguiu-se um longo período de trevas. O que havia por descobrir, descoberto já fôra. $\mathrm{O}$ prestígio de Aristóteles nos círculos religiosos dominantes afastava qualquer tentativa de pesquisa. Inclusive nos campos que o próprio Aristóteles declarava-se insatisfeito com seus resultados e conclusões. Quanto a insetos, na Idade Média, ter piolhos ou conviver com pulgas e percevejos era tido como virtuosa manifestação de humildade, de santa conformação com a vontade de Deus. Um passaporte visado para o céu. Afinal, piolhos não foram também criados por Deus? Uma atitude sem antagonismo com o discurso de certos eco-maníacos de hoje.

Foi a quinta fase, o Homem aceitando com santa resignação o parasitismo pelos insetos.

Após Guttenberg, a descoberta da imprensa veio possibilitar o intercâmbio de conhecimentos, a intercomunicação entre os estudiosos de diferentes países.

Mas foi somente em 1602, que Aldrovandi publicou "De Animalibus Insectis", obra que marcou a retomada do estudo científico dos insetos. Ainda no século XVII, autores como Bacon e Descartes ousavam propor a metodologia científica: observação e experimentação, objetividade e racionalidade. Swammerdam (anatomia interna da abelha, evolução do óvulo da rã, hemáceas, contração do miocárdio), van Leeuwenhoek (com o seu microscópio), Fabricius (ensaios taxonômicos) e Harvey (omne vivum ex ovo) foram progressivamente enriquecendo a biologia.

René Antoine Ferchauld de Réaumur, mundialmente conhecido por sua escala termométrica, publicou entre 1734 e 1742 suas "Memoires pour servir a l'histoire des Insectes", - primeiro livro sobre entomologia. Ȧquela época, Linnaeus lançava as bases da taxonomia que iria permitir a organização e o rápido desenvolvimento das ciências naturais.
Mas foi somente na primeira metade do século XIX que a entomologia foi individualizada como ciência e surgiram as Sociedades de Entomologia de Paris (1832), de Londres (1833) e de Stettin (1887).

No século passado, estabeleceu-se também o conceito de insetos como pragas. Com seu crescimento rápido, precisando acumular reservas para a fase inativa, os insetos são conhecidos por sua voracidade. Voracidade temida pelos horticultores, os silvicultores e os fruticultores em primeiro lugar, no tempo.

Já em 1800, Erasmus Darwin publicava "Phytologia, or the Philosophy of Agriculture and Gardening", levantando a hipótese de combater as pragas utilizando espécies competitivas ou predadoras. Em 1843, em Milão, a Sociedade para o Desenvolvimento da Ciência, instituía um prêmio para trabalhos sobre insetos "carnívoros", predadores de insetos.

Desde 1870 , sucederam-se as tentativas de utilização do que conhecemos hoje como combate biológico e após muitos insucessos, surgiu a espetacular vitória de Koebele, salvando os laranjais da Califórnia infestados pela Icerya, graças a introdução de Vedalia, importada da Austrália.

Com o desenvolvimento da indústria química, surgiram, sobretudo após a Segunda Guerra Mundial, os defensivos agrícolas que pareceram dispensar novos investimentos em pesquisas sobre o controle biológico. Todavia, o uso revelou inconvenientes, por vezes graves, inspirando o interesse pelos métodos biológicos de controle, empregando-se não só espécies competitivas e predadoras, mas também fungos e vírus patogênicos para os insetos.

Em 1878, Patrick Manson comprovava a transmissão da Wuchereria bancrofti por Culex. Os insetos ganhavam importância médica e uma nova era inaugurava-se. Nascia a Entomologia Médica.

Foi um longo caminho, mais de três mil anos, desde o reconhecimento de insetos como produtores de seda e mel até a sua identificação como vetores de doenças. Isto apesar das devastadoras epidemias de peste como as ocorridas no império romano durante o século VI, a pandemia do século XIV, responsável, segundo Hecker, por 25.000.000 de óbitos na Europa, depois da grande epidemia de Londres, matando, em 1664, nada menos de 70.000 dos 460.000 habitantes da cidade e tantas outras epidemias no Mediterrâneo, India e China que sabemos dramáticas mas sobre as quais faltam dados quantitativos. 
A entomologia passou a interessar direta ou indiretamente, toda a comunidade científica. Aprofundaram-se os estudos taxonômicos, começou-se a esmiuçar a biologia de insetos passando-se à sua ecologia e etologia. Iniciou-se o estudo das cadeias de transmissão, que evoluiria para o estudo dos ecosistemas de transmissão e as tentativas de elaboração de modelos matemáticos. Os trabalhos publicado por Forattini e sua equipe assinalam o ingresso da entomologia médica brasileira na moderna fase de conceituação ecológica.

O desenvolvimento da entomologia médica rendeu vultosos dividendos ao desenvolvimento da epidemiologia.

Esta incursão pelo passado, mais do que uma cronologia, pretende investigar a evolução do pensamento científico com relação a entomologia.

Da procura de alimento entre os pêlos do vizinho, até a arte refinada de produzir seda e mel. A revelação de que insetos começavam a importunar os humanos, inspirando a pesquisa de fórmulas para repeli--los ou matá-los. A pesquisa do naturalista e filósofo Aristóteles, a transformação de certos hematófagos em passaporte visado para o céu durante as trevas da Idade Média, a busca da taxonomia e finalmente a adoção de uma sistemática permitindo a troca de informações.

$O$ advento da imprensa possibilitou a divulgação de trabalhos científicos que pouco significariam sem a identificação taxonômica, a identificação precisa e em linguagem universal, do objeto da pesquisa.

Enquanto o conhecimento evoluía, milhões de vidas eram ceifadas e ninguém suspeitava que insetos estariam envolvidos como vetores. A lição do passado continua atual.

Certamente, apesar da respeitável soma de conhecimentos já disponíveis, ainda não sabemos tudo acerca do papel dos insetos na transmissão de doenças, pouco sabemos acerca de ecossistemas de transmissão e o controle biológico dos insetos vetores de doenças ainda é um campo a ser explorado. O controle genético, já tentado eventualmente, ainda aguarda novas pesquisas. $O$ cultivo de vírus em células vivas de insetos já rendeu algumas informações úteis, mas permanece um campo a ser explorado.

Dobzhansky, o pai da genética moderna, no final de sua vida admirável, investigava em Davis, Califórnia, o comportamento de gerações sucessivas de Drosophila, abrindo uma nova possibilidade para o estudo de componentes genéticos do comportamento animal, estudo que ganha nova dimensão com a sociobiologia de Wilson.

As pesquisas modernas sobre a comunicação entre os insetos, sobretudo sobre os mensageiros químicos, adquire importância crescente sob o ponto de vista holístico.

Assim vemos que a Entomologia evoluiu rapidamente, da coleção de caixas com naftalina e insetos espetados em alfinetes e religiosamente etiquetados, para um nível de interesse universal. Um nível de interesse holístico inatingível se os insetos naquelas caixas com naftalina não estivessem escrupulosamente etiquetados. Um nível que interessa à produção e conservação de alimentos, à genética, à virulogia, à transmissão de diferentes enfermidades, à ciência do comportamento, à Ecologia Humana, os estilos de vida e, consequientemente, a qualidade de vida. Em síntese, à Saúde Pública.

Diante de tamanha importância e tão ricas possibilidades oferecidas, quais as espectativas atuais nos países em desenvolvimento?

Em 1975, a UNESCO publicou diversos volumes sobre "Políticas Científicas", reunindo resultados de pomposas reuniões internacionais. $\mathrm{O}$ volume 3 é dedicado à América Latina.

No que concerne ao Terceiro Mundo, cada delegação esmerou-se na louvação do respectivo governo, aplicando-se zelosamente na enumeração de feitos e propósitos. Feitos infelizmente de impacto pouco significativo e propósitos revelando lamentável miopia no enfoque de questões científicas, limitando-se os objetivos àqueles que conduziam ao crescimento econômico, impropriamente denominado "desenvolvimento" econômico.

Denominador comum foi a transferência de tecnologia.

As chamadas Políticas Científicas pouco se preocuparam com o incremento do conhecimento científico.

Geração de conhecimento em nível nacional, condição essencial para o desenvolvimento ou a simples transferência de tecnologias, nunca foi objetivamente encarado pelas chamadas Políticas Científicas.

Aquela obsessão pela transferência de tecnologia sobrevive até hoje.

Perguntado sobre a sua política de ciência e tecnologia, respondeu-me Zeledon, um sábio ministro da Costa Risca: "Antes de mais na- 
da, fortalecer e aprimorar o que já existe em nosso país." Política Científica inteligente: identificar e fortalecer o existente. Prestigiar as escolas existentes.

Confesso que, tendo testemunhado as crises e a luta pela sobrevivência de respeitáveis unidades universitárias e de institutos como o Adolfo Lutz, o Butantan, o Agronômico de Campinas, o Instituto Biológico de São Paulo, - Museu Goeldi do Pará, o Instituto de Pesquisas da Amazônia, o Instituto Oswaldo Cruz, - Instituto Evandro Chagas, e tantos outros, não consegui evitar uma comparação e uma conclusão desoladora: nossas políticas científicas, se é que se pretende ter existido uma política científica no Brasil, podem ter atendido os interesses do grupo momentaneamente dominante mas não deram prioridade ao fortalecimento e sequer à sobrevivência de instituições com enorme acervo de competência a duras penas desenvolvida. Não tem sido fácil distinguir a macro-competência nacional no cenário turbulento das micro-competências entronizadas pelo poder de plantão.

Hoje, vivemos no Brasil uma época de mudanças e sempre que há mudança, surgem esperanças. Não estou pessoalmente envolvido e muito menos interessado em envolver-me no processo em curso. Diz-se que "Desde a mais remota antiguidade os septuagenários são reconhecidos como seres esquisitos."

Mas, lembrando os muitos homens de ciência que conheci, as escolas que pereceram à inanição, a minha repugnância, quando militava no $\mathrm{CNPq}$ pela participação da "comunidade científica" restrita aos grupos dominantes, não posso deixar de desejar que se encontre uma fórmula para tentar elaborar uma política científica, não com a participação de grupos privilegiados pelo poder, mas com a participação realmente democrática dos que fazem ciência no país. Não é tão difícil identificá-los. Num comitê internacional que integrei durante três anos, solicitava-se aos postulantes que, em seu curriculum citassem e juntassem cópia de dois trabalhos significativos, publicados nos últimos cinco anos. Nada de currícula avaliados por quilo de papel. A nível nacional, com auxílio de computadores, a tarefa é exequiível.

Que se confira prioridade à preservação do que existe de capaz e produtivo e que não deveria ser condenado a inanição quando parcos recursos são vorazmente sugados por modismos, por vezes legítimos, mas sempre dispendiosos. Quanto se gastou na importação de equipamentos custosos, hoje abandonados em diferentes instituições, sem jamais terem sido atilizados, quais torres de marfim sem história, doadas a um pesquisador eventualmente bem visto pelo poder e em função de outros critérios que não a avaliação da equipe que iria utilizá-los?

Uma das idéias importadas sem nenhum espírito crítico, posso dizê-lo porque numa idade inexperiente eu mesmo a defendi, foi a luta contra a dispersão de recursos. "Dispersão de recursos" transformou-se em expressão mágica. Quaisquer medidas para combatê-la eram calorosamente aplaudidas sem análise crítica. Poucos percebiam que, a pretexto de lutar contra a dispersão, o que se visava era a centralização com espírito autoritário.

Se a soma total dos recursos era insuficiente, a fusão das partes em um só todo não iria efetuar o milagre da multiplicação dos pães.

Se alguma das partes geria mal os seus pequenos recursos, o Estado, ao absorvê-los todos não os gerenciou melhor.

A centralização, mesmo sob mãos eventualmente competentes e honestas, tem sido catastrófica.

No que concerne a Política Científica, seria desejável a ampla participação democrática de quem realmente faz ciência, sem discriminações e sem intolerâncias, fazendo-se a profilaxia da dominação por grupos, e definindo-se sobretudo conceitos voltados para o desenvolvimento do potencial científico.

A implementação da Política Científica descentralizada poderia atrair mais recursos de origem setorial e da própria sociedade.

Em cada Ministério existiu, não sei se ainda existe, uma Secretaria de Ciência e Tecnologia, operando em harmonia com o Conselho $\mathrm{Na}$ cional de Pesquisas. Algumas daquelas Secretarias podem não ter atingido o nível de eficiência desejado. O critério para o seu preenchimento pode ter sido eventualmente eclipsado por interesses eleitoreiros. Mas nem tudo se cura com uma amputação. Aquelas Secretarias, sob comando competente e com orçamento próprio, em harmonia com um comando central, ainda representariam uma alternativa para otimização da implementação de uma eventual Política Científica, elaborada e comandada por um órgão supremo de coordenação participativa, sensível aos problemas setoriais.

A criação do Ministério da Ciência e Tecnologia representa um grande passo. Criou-se um ponto de convergência que poderá eliminar a perplexidade dos que se empenhavam em 
descobrir qual a tendência de cada agência financiadora de pesquisas. Vivemos uma nova experiência rica em esperanças.

Uma Política Científica contemplando prioritariamente o desenvolvimento do saber, e não restrita a questões ligadas ao crescimento econômico, se inclui entre aquelas esperanças.

A entomologia, que ainda não gera diretamente qualquer produto comercializável, muito depende, como todas as ciências básicas, da preocupação com o incremento do saber.

Seu potencial ultrapassa os limites das velhas e sempre indispensáveis caixas dos taxonomistas: a inteligência de ecossistemas, a nova epidemiologia holística, a moderna genética e engenharia genética, a dinâmica de populações, a produção de alimentos, a qualidade de vida, as ciências do comportamento, a ecologia humana e mesmo a compreensão da própria vida neste planeta, encontrarão importantes subsídios numa entomologia moderna $\mathrm{e}$ atuante.

Numa visão prospectiva, não se pode desprezar a priori, a hipótese de alguns futurólogos encarando os insetos como fonte alternativa de proteína animal para alimentação da população humana em crescimento explosivo. Naturalmente, serão insetos produzidos em grandes criatórios, devidamente pasteurizados, com o carimbo do SIF, certificados como isentos de contaminantes químicos e, depois de aromatizados artificialmente, artisticamente embalados para venda a um público exigente nos supermercados do século XXI, a um preço provavelmente além do alcance de um trabalhador ganhando um salário mínimo.

O potencial da entomologia é tão grande que mesmo uma contribuição para a produção comercializável, além do combate biológico às pragas, se inclui entre as possibilidades.

Nos países do Terceiro Mundo, o futuro da saúde, da qualidade de vida, do conhecimento como um todo, está vinculado ao crescimento de escolas de Entomologia como esta que hoje comemora o seu cinquientenário. Crescimento que sempre irá depender também de uma Política Científica priorizando o Saber.

Disse "também", porque o ingrediente básico, uma equipe competente e capaz de formar novas gerações, este existe e está provado durante meio século. Os nossos sucessores comemorarão o seu centenário como hoje celebramos o seu cinquientenário: com respeito, admiração e gratidão.

Paulo de Almeida Machado Ministro da Saúde (1974-1979) 